\title{
"Hvad de skrifva i tidningare i Stockholm" Prensa y opinión pública en Suecia ante la emigración temprana a América (1861-1865)
}

\author{
Oscar Álvarez Gila* \\ Universidad del País Vasco/ Euskal Herriko Unibertsitatea \\ Vitoria-Gasteiz - Álava - España
}

\section{Resumen}

Este artículo analiza el modo en el que la prensa sueca presentó la emigración a América en el periodo comprendido entre 1861 y 1865, es decir, en los años de la Guerra Civil en Estados Unidos. Este país comenzaba a ser, ya por entonces, el principal receptor de emigrantes suecos, en un proceso que se alargaría hasta la tercera década del siglo XX. Basándonos en un corpus de casi un millar de referencias periodísticas, estudiamos el modo en el que se conformó la temprana opinión pública ante la emigración. A diferencia de lo que caracterizaría el primer tercio del siglo XX, a mediados del XIX los periódicos suecos ofrecían una visión equidistante, y hasta cierto punto positiva, de la emigración.

\section{Palabras clave}

Opinión pública - Emigración - Suecia - Prensa

* Doctor en Historia. Profesor Titular de Historia de América en el Departamento de Historia Medieval, Moderna y de América, Facultad de Letras. Universidad del País Vasco (Euskal Herriko Unibertsitatea).E-mail: oscar.alvarez.gila@gmail.com. 


\section{"What they write in the newspapers of Stockholm" \\ Press and Public Opinion in Sweden on Early Emigration to America (1861-1865)}

Oscar Álvarez Gila

In this article we analyze how Swedish press understood emigration to America during the years between 1861 and 1865, when the American Civil War was ongoing. The United Stated already were, by then, the most important recipient of Swedish immigrants abroad, in a process that would last up to the third decade of the 20th century. Based upon a corpus of almost a thousand articles and news, we study how the early public opinion on emigration was created. In contrast with what characterized the first third of the 20th century, by the middle of the 19th century the Swedish newspapers offered a quite equidistant, almost positive view on emigration.

\section{Keywords}

Public opinion - Emigration - Sweden - Press 


\section{Prensa sueca en tiempos de emigración ${ }^{1}$}

Entre 1851, fecha en la que comenzaron a registrarse de forma sistemática en Suecia las estadísticas sobre migraciones, hasta 1950, se calcula que un total de aproximadamente 1.200.000 nacionales suecos emigraron fuera de Europa, la inmensa mayoría de ellos a los Estados Unidos $^{2}$. Esta cifra no debe entenderse tanto desde sus valores absolutos, como en sus proporciones relativas respecto a la población total del país: como ya hiciera notar tempranamente Hovde, si tomamos en cuenta ambos factores, Suecia (y en general Escandinavia) fue la región europea en la que la emigración ultramarina fue más elevada en proporción a su población ${ }^{3}$. Se añade a esto el bajo índice de retornados, convirtiendo en emigrantes permanentes a las cuatro quintas partes de quienes abandonaron Suecia en este periodo. ${ }^{4} \mathrm{El}$ impacto de este fenómeno fue tal que ya en 1913 el demógrafo sueco Gustav Sundbärg era capaz de afirmar categóricamente que "analizar la 'emigración sueca' era lo mismo que analizar 'Suecia', dado que apenas hay un solo pro-

1 Este artículo se deriva de una ayuda del Programa de Movilidad del Personal Investigador del Departamento de Educación, Política Lingüística y Cultura del Gobierno Vasco "Ikermugikortasuna-2016". Forma parte igualmente de la actividad del grupo consolidado de investigación del sistema vasco "País Vasco, Europa y América: Vínculos y relaciones atlánticas” (IT938-16).

2 Datos tomados de SCOTT, F.D. "Sweden's Constructive Opposition to Emigration". The Fournal of Modern History: n.37-3, p. 307-335, 1965 (cit. en p. 313). Scott presenta un total de 1.190.784 emigrantes suecos "a Ultramar" en este periodo, tomando en consideración el sumatorio total de partidas, sin deducir los procesos de retorno, y sin determinar el impacto de cuestiones que puedan matizar esta cifra global, como las reemigraciones. En todo caso, las cifra nos sirve como un buen indicador de la importancia relativa de la emigración en su contexto demográfico. Scott añade igualmente que del total de emigrantes ultramarinos, nada menos que 1.141.969 habrían elegido Estados Unidos como lugar de destino.

3 HOVDE, B.J. "Notes on the Effects of Emigration upon Scandinavia". The Journal of Modern History, Chicago: n.6-3, p. 253-279, 1934 (cit. en p. 254). También CARLSSON, S. "Chronology and Composition of Swedish Emigration to America". In RUMBLOM, H. y NORMAN, H. (eds.). From Sweden to America: A History of the Migration, Minneapolis, University of Minessota Press, 1976, p. 114-148.

4 Sobre los ritmos y cifras de la emigración ultramarina sueca en el contexto de los países nórdicos, sigue siendo de utilidad la obra de cojunto de NORMAN, H. y RUMBLOM, H. Transatlantic Connections. Nordic Migration to the New World after 1800, Oslo, Norwegian University Press, 1988 (especialmente pp. 4-21). 
blema político, social o económico en nuestro país que no ha sido condicionado, directa o indirectamente, por el fenómeno de la emigración" 5 .

Como ocurrera en otros países europeos que experimentaron durante aquel mismo periodo los efectos de la conocida como emigración masiva $^{6}$, la opinión pública, y más en concreto aquella canalizada a través de los medios de comunicación escritos, dedicó a la cuestión migratoria un interés creciente, que fue más allá de la mera descripción narrativa del proceso, para indagar y debatir sobre sus causas y consecuencias. Ya desde que en 1899 Yarros hiciera notar la "tremenda influencia e importancia de los periódicos como órgano de la opinión pública" y, más aún, como "director y moldeador de dicha opinión"7, los estudios sobre la prensa y su posición centran en la sociedad, a caballo entre la información, la opinión y la ideología, han tenido una larga tradición en el ámbito de las ciencias sociales y, también, de la historia. En el caso de Suecia, destaca sobre todo el carácter temprano del desarrollo de un sistema de prensa destinado al gran público, en comparación con otros países europeos. Algunos autores han hecho remontar el precoz éxito de la prensa sueca al periodo denominado "Era de la Libertad", entre 1718 y 1772, momento en el cual el relajo de los sistemas de censura en la difusión de escritos llevó a un crecimiento y diversificación de las cabeceras periodísticas en $\mathrm{Suecia}^{8}$. Ya en el siglo XIX, como señalan Gustafsson y Rydén, el hecho determinante que marcaría la evolución posterior de la prensa vino dado por la introducción de la prensa popular; es decir, aquella que, siguiendo los

5 Citado por GOODMAN, A. "Nation of Migrants, Historians of Migration". Fournal of American Ethnic History: n.34-4, p. 7-16, 2015 (cit. en p. 11).

6 Sobre este periodo, véase MÖRNER, M. Aventureros y proletarios. Los emigrantes en Hispanoamérica, Madrid, Fundación Mapfre América, 1992.

7 "Sociologists have not failed to recognize the tremendous influence and importance of the newspaper as an organ of public opinion, and some of them have gone farther and adverted to the press as the director and molder of such opinion". YARROS, V.S. "The Press and Public Opinion". American fournal of Sociology: n.5-3, p. 372-382, 1899 (cit. en p. 372).

8 GUSTAFSSON, K.E. y RYDÉN, P. A History of the Press in Sweden, Göteborg, Nordicom-Göteborgs Universitet, 2010 (cit. en p. 27-28). 
modelos de empresas periodísticas que habían tenido éxito en otros países, introdujeron un nuevo tipo de periódico de precio más reducido, contenidos más frívolos, con menos política y más entretenimiento ${ }^{9}$. Como resultado, durante las décadas de 1860 y 1870 aumentaría el número de periódicos en el país, al no quedar ya constreñida la publicación de cabeceras solamente a la capital y a las ciudades más importantes. Así, junto a los diarios tradicionales de las zonas urbanas, se sumaría una diversidad de periódicos locales, por lo general de no más de cuatro páginas y de periodicidad semanal o bisemanal ${ }^{10}$. Aparte de los cambios sociales derivados de la incipiente industrialización y de los efectos de la mejora en las comunicaciones (que permitía el conocimiento, y al mismo tiempo alentaba el interés por las noticias más allá del estricto ámbito local), se ha señalado igualmente la generalización del alfabetismo entre la población sueca. Nilsson cita, en este sentido, los trabajos de Egil Johansson y de Johan Söderberg que estimaban, respectivamente, que un 90\% de la población sueca sabía leer y un 20-25\% era capaz de escribir a comienzos del siglo XIX. Si bien es crítico con los diferentes significados atribuídos al concepto de "alfabetización" en contextos sociales y nacionales diferentes, el propio Nilsson acepta tasas muy similares en ambos parámetros para la mitad del siglo, incluso en las áreas rurales en regiones como Escania ${ }^{11}$. Esto significó, como señalaba Hovde, que la población sueca "a lo largo de todo el periodo de emigración había mantenido un elevado nivel cultural; por lo tanto habían sido tan conscientes del fenómeno de la emigración como en cualquier otra parte de Europa [lo que se] manifestó en una larga producción escrita de debate"12.

9 GUSTAFSSON y RYDÉN. A History of the..., 2010, p. 97.

${ }^{10}$ GUSTAFSSON y RYDÉN. A History of the..., 2010, p. 87.

${ }^{11}$ NILSSON, A. "What Do Literacy Rates in the 19th Century Really Signify? New Light on and old Problem from Unique Swedish Data”. Paedagogica Historica: n.35-2, p. 274-296, 1999 (cit. en p. 284 y 293).

12 “(..) through the whole period of emigration, moreover, they have had a high standard of culture; they have therefore been quite as aware of the phenomenon of emigration as any part of Europe. This alertness has manifested itself in a large literature of discussion". HOVDE. "Notes on the Effects...". 1934, p. 254. 
El éxito de la prensa popular vino también de la mano de ciertas modificaciones en la propia estructura interna de los diarios y el modo en el que se clasificaba, jerarquizaba y presentaba la información, haciendo la lectura de la prensa al mismo tiempo más asequible y más atractiva. El sistema, conocido como "news-item", consistía básicamente en que cada porción de contenido (ya fuera una noticia, un comentario o un artículo de opinión), debía ser presentado de forma separada visualmente, con su propio título, aunque no fuera más que mediante el procedimiento de destacar con letra negrita la primera frase del texto. Si bien fue una cabecera regional, el Nerikes Allehanda de Örebro, el primero en implementar este sistema, el éxito del sistema y su generalización se produciría tras ser adoptado en 1859 por uno de los principales periódicos urbanos de Suecia, el Göteborgsposten ${ }^{13}$.

Para este momento la emigración sueca a América, aunque aún no había alcanzado las proporciones a las que llegaría en el último cuarto de siglo, ya era un fenómeno visible para cualquier observador atento de la realidad social en muchas partes de Suecia. Se admite que la migración contemporánea sueca a América había comenzado en el contexto de la reorganización europea tras las guerras napoleónicas, desde la década de $1820^{14}$, y que las primeras salidas organizadas de grupos de emigrantes del país se habían comenzado a producir ya desde la década de $1840^{15}$, vinculados en gran medida en un primer momento a motivaciones no tanto económicas como religiosas, ya que muchos de ellos se asentaron en América al hilo las predicaciones del pastor pietista Eric Jansson (o Janson), cuyos seguidores crearon las primeras

${ }^{13}$ GUSTAFSSON y RYDÉN. A History of the..., 2010, p. 100-101.

${ }^{14}$ OLSSON, N.W. Swedish Passenger Arrivals to New York, 1820-1850, Chicago, Swedish American Historical Society, 1967 (cit. en p. III). También FRIMAN, Axel. "Svensk utvandring till Nordamerika 1820-1850". Personhistorisk tidskrift , Johanneshov (Sweden): n.70-1/2, p. 18-35, 1974.

${ }^{15}$ SÖDERBERG, K. Den första mass-utvandringen. En studie av befolkningsrörlighet och emigration utgående från Alfta socken i Hälsingland, 1846-1895, Ph.D. dissertation, Universitetet i Umeå (Suecia), 1981 (cit. en p. 20). 
colonias suecas en Estados Unidos, sentando las bases para la continuación del fenómeno migratorio en posteriores y sucesivas oleadas ${ }^{16}$.

Se suele de este modo aceptar que la migración sueca -y en general, de toda Escandinavia- no alcanzaría cifras significativas hasta mediados de la década de 1860 . Una primera oleada migratoria abarcó desde aproximadamente 1865 hasta 1873; este periodo, durante el que se calcula que pudo producirse el traslado a América de unos 120.000 emigrantes, ha venido a ser conocido en la historiografía como la "emigración por el hambre" (en un movimiento que los contemporáneos vinieron a explicar mediante la existencia de una serie de años seguidos de malas cosechas en el agro sueco $)^{17}$. No obstante, el momento realmente masivo de la emigración sueca ultramarina aún estaba por llegar. Tras un breve periodo de ralentización, la migración volvió a tomar impulso en 1879, iniciándose una segunda oleada que llevaría a América, entre ese año y 1893, unos 485.000 emigrantes, con unas tasas notablemente elevadas de emigración en algunos años.

\section{La opinión publicada en Suecia ante la emigración: panora- ma historiográfico}

$\mathrm{Al}$ igual que en otros países y regiones europeos que estaban experimentando, por aquellos mismos años, los efectos de las grandes emigraciones, también la opinión pública sueca -y muy especialmente aquella encauzada y construida desde los medios de comunicación, es decir, tanto la prensa escrita como, en un momento más avanzado,

\footnotetext{
16 "First, it contributed to a substantial increase in the spread of information about America in Sweden in the 1840's. Second, it can easily be established that there were definite links betweeen the Eric Jansonist movement and other subsequent emigration from other parts of Sweden. Third, the Eric Jansonist emigration led to the establishment of a string of Swedish colonies strategically situated in the American Mid-West”. SÖDERBERG. Den första mass..., 1981 p. 230.

${ }^{17}$ BEIJBOM, U. Swedes in Chicago: a Demographic and Social Study of the 1846-1880 Immigration, Ph.D. dissertation, Uppsalas Universitetet (Suecia), 1972 (passim). Igualmente PUSKÁS, S. "Some Recent Results of Historic Researches on International Migration”. Acta Historica Academiae Scientiarum Hungaricae , Johanneshov (Sweden): n.23, p. 151-169, 1977 (cit. en p. 163).
} 
otros medios de difusión como el cine $^{18}$ o la radio- se vio compelida a debatir y valorar las causas, efectos, orígenes y consecuencias que la atracción del continente americano para tantos de sus compatriotas tendría sobre ellos, sus familias, y en general, sobre el propio presente y futuro de Suecia. La emigración se convirtió, de hecho, en una metáfora desde la que se discutía, sobre la necesidad de modernizar la sociedad, la política y la economía suecas en unos momentos de profundos cambios en todos esos aspectos a escala continental ${ }^{19}$. Además, como señala Hovde, ayudó a la visibilidad y difusión del debate migratorio el "alto standard de cultura" ${ }^{20}$ del que disfrutaba una población cuyos índices de alfabetismo eran, como ya hemos visto, tempranamente elevados en el contexto europeo, permitiendo de ese modo un acceso más directo que en otras zonas del continente a la opinión escrita y publicada en la prensa.

La historiografía también ha dedicado su atención, en trabajos monográficos así como en estudios más generales sobre la emigración y su impacto, a la cuestión de la opinión pública sueca con respecto al fenómeno migratorio. Uno de los trabajos pioneros es la obra de Anne-Sofie Kälvermark, Reacción ante la emigración. La cuestión migratoria en el debate y la política suecas (publicada por la universidad de Uppsala en $1972)^{21}$. Kälvermark centra su análisis en un periodo extremadamente breve, el correspondiente a 1901-1904. si bien a la hora de elaborar el contexto, tanto migratorio como político y de opinión, se retrotrae has-

${ }^{18}$ Para el caso del cine, es especialmente interesante y bien documentado el trabajo de WALLENGREN, A.-K. Welcome Home Mr Swanson. Swedish Emigrants and Swedishness on Film, Lund, Nordic Academic Press, 2014.

${ }^{19}$ Lögfren asegura, más aún, que la propia corriente migratoria contribuyó en Suecia a acelerar y afianzar el proceso modernizador, al asegurar cierta estabilidad política debido al alivio de la presión sociodemográfica proporcionado por la emigración. LÖGFREN, O. "Materializing the Nation in Sweden and America". Ethnos, Stockholm, n.58/3-4, p. 161-196, 1993.

${ }^{20}$ HOVDE. "Notes on the Effects...", 1934, p. 254.

${ }^{21}$ KÄLVERMARK, A-S. Reaktionen mot utvandringen. Emigrationsfragan i svensk debatt och politik 19011904, Uppsala, Uppsalas Universitetet, 1972 (=Studia Historica Upsaliensia XLI). 
ta la década de 1860. Basado en fuentes administrativas y legislativas ${ }^{22}$, así como en el análisis de la prensa nacional, el principal argumento defendido por Kälvermark es que la emigración sueca se mantuvo durante largo tiempo sin que hubiera una reacción marcada en la opinión pública y, consecuentemente, el debate político hasta un momento muy tardío, que sitúa ya en el siglo XX, sin dejar tiempo para que se desarrollara una política nacional en Suecia relativa a la emigración ${ }^{23}$.

En cierta medida, el trabajo de Kälvermark sigue y ha marcado la línea de previos y posteriores estudios monográficos igualmente centrados en la opinión pública. Diversos estudios, por ejemplo, han reafirmado la noción de que Suecia no experimentó en su opinión pública el surgimiento de campañas masivas y, en gran medida, institucionalizadas contra la emigración hasta fechas muy tardías, ya comenzado el siglo XX. Estos autores reconocen, ciertamente, la existencia de voces contrarias a la emigración durante todo el siglo precedente. Barton, en su obra $A$ Folk Divided, hace una exhaustiva recopilación de testimonios publicados y difundidos por folletos y otros medios que criticaban la emigración y denunciaban aquellos efecto que tildaban de perniciosos tanto para el país en su conjunto como para los emigrantes como individuos $^{24}$. Tales voces habrían comenzado a hacerse oír, de hecho, desde los mismos inicios del proceso migratorio ${ }^{25}$. No obstante las críticas habrían sido muy minoritarias, debido a la "actitud esquizofrénica" que, según la definición de Scott, presentaba la sociedad sueca ante la emigración, dado que:

${ }^{22}$ Entre otras, informes de gobernadores provinciales sobre emigración, elaborados en 1882, así como los debates sobre tema migratorio en el Parlamento sueco y la legislación emanada del mismo desde 1884 .

${ }^{23}$ Esta es la idea principal que destaca, y coincidimos con él, W. WESTERBERG en su reseña de la obra en Swedish American Historical Quarterly, Chicago: n.25/2, p. 158-159, 1974.

${ }^{24}$ BARTON, H.A. A Folk Divided. Homeland Swedes and Swedish Americans, 1840-1940, Carbondale, Souther Illinois University Press, 1994 (especialmente pp. 20-80).

${ }^{25}$ Por ejemplo, RUNEBY, N. "Gustaf Unonius and Propaganda against Emigration”. Swedish Pioneer Historical Quarterly, Chicago: n.23, p. 94-107, 1973. 
unlike the reaction in Germany, where agricultural crises such as those of 1816-17 aroused strung proemigration sentiment and where economic betterment and national unification in the 1879's unleashed patriotic ourtbusts against emigration, in Sweden the swings of opinion were less violent. Swedish opinion clashed in a running debate in which diverse points of view were repeatedly expressed ${ }^{26}$.

En este punto, tanto los modos como sobre todo el contenido de los ataques y críticas a la emigración sería, por otra parte, muy similares a las que se habían desarrollado o se estaban desarrollando simultáneamente en otros países europeos con fuertes saldos emigratorios ${ }^{27}$. Así por ejemplo, como señala Alm, hablando de los años comprendidos entre el comienzo del siglo y la Primera Guerra Mundial, el "gran debate en Suecia respecto a la emigración” se centró en determinar el mejor modo para ponerle fin, dado que "se consideraba que quitaba a Suecia su fuerza de trabajo e impedía el desarrollo económico del país" ${ }^{\text {"28 }}$. Otros

${ }^{26}$ SCOTT, F.D. "Sweden's Constructive Opposition to Emigration". The fournal of Modern History, Chicago: n.37-3, p. 307-335, 1965 (cit. en p. 307). De hecho, Scott sitúa el inicio de un incipiente discurso antiemigración ya en el siglo XVIII, cuando se expresaron las primeras reflexiones académicas sobre las causas de la emigración, dejando como poso una serie de leyes antiemigratorias que no se abandonaron completamente hasta la década de 1860. Señala ademá que en esa década la legislación cambió hacia fijarse más en la protección del emigrante, antes que en el objetivo de evitar la emigración.

${ }^{27}$ Un buen ejemplo de esto podría ser, en el sur del continente, las campañas migratorias desarrolladas en el País Vasco, casi desde el inicio de las migraciones ultramarinas contemporáneas, en la década de 1840. Como demuestran los trabajos, entre otros, de Azcona Pastor, Apaolaza Avila, Tápiz Fernández y Alvarez Gila, la opinión publicada y dirigida desde las élites políticas, económicas y eclesiásticas vascas coincidieron de manera casi unánime en atribuir a la emigración efectos perniciosos de todo tipo para el país, urgiendo la adopción de medidas para paralizar, o en su caso limitar, su alcance. Véase. AZCONA PASTOR, J.M. "Las campañas de prensa antiemigración: José Colá y Goiti y el caso vasco-navarro". 200 años de Iberoamérica (1810-2010). Congreso Internacional. Actas del XIV Encuentro de Latinoamericanos Españoles, Santiago de Compostela, Universidade, 2010, pp. 1061-1098. APAOLAZA AVILA, U. "Amerikara joandako emigrantearen irudia Euskal Herriko prentsan (1876-1936)". Kondaira, Bilbao: n.9, 2009, on-line. ÁLVAREZ GILA, O. y TÁPIZ FERNÁNDEZ, J.M. "Prensa nacionalista vasca y emigración a América (1900-1936)". Anuario de Estudios Americanos, Sevilla: n. LIII/1, p. 233-260, 1996.

28“During (..) this period, there was a great debate in Sweden concerning the emigration to America and how to put an end to it. Emigration was believed to drain Sweden of its workforce and to 
argumentos iban en la línea de idealizar el modo de vida tradicional, o en denunciar la falta de "patriotismo" de los emigrantes; no faltaba tampoco quienes, dando la vuelta al argumento, achacaban la "manía de la emigración" a las duras condiciones económicas, las crisis y la rigidez de la estructuración social tradicional de Suecia, que presentaba limitadas vías de ascenso en comparación con las sociedades americanas. Diversos pensadores y opinion-makers del último cuarto del siglo XIX hacían hincapié, en esta misma línea, en priorizar los factores de atracción, justificando la existencia de la emigración en una cierta imagen negativa de Suecia, vinculada a la noción de atraso económico y político del país; tal es el caso, por ejemplo, de Ernst Beckman, que en su obra Amerikanstudier defendía la necesidad de "traer América a Suecia" 29 , en el sentido de promover la modernización, como el medio más efectivo de "mantener la emigración en niveles adecuados"30.

También las políticas estatales, siguiendo este mismo razonamiento, habrían llegado de forma tardía a preocuparse por la cuestión migratoria. Según Hovde, "entre 1865 y 1882 se presentaron diversas leyes en el Parlamento con el propósito de restringir el derecho a emigrar; pero ninguna fue aprobada". Y más aún, "entre 1882 y 1904 ni siquiera se llegó a presentar ninguna proposición legislativa"31. Asi, no sería hasta los primeros años del siglo XX, entre 1907 y 1913, que llegó a funcionar en el parlamento sueco una Comisión parlamentaria de emigración; y ligado a ella se organizó entre 1907 y 1925 una institución denominada Nationalföreningen mot emigrationen ("Asociación

impede the country's economic development". ALM, M. "America and the Future of Sweden: Americanization as Controlled Modernization", American Studies in Scandinavia, Helsinki: n.35, p. 64-72, 2003 (cit. en p.65).

29 "Estudios americanos": Estocolmo, 1882, p. 182.

${ }^{30}$ HOVDE. "Notes on the Effects...", 1934, p. 254. Se sumaría a ello la importancia otorgada a las remesas enviadas por los emigrantes a sus familias en Suecia, que el propio Beckman estimaba que habrían alcanzado la nada despreciable suma de 3 millones de dólares, solo en 1882.

31 "Between 1865 and 1882, several bills were introduced in the Riksdag with the purpose of placing restrictions upon the freedom to emigrate; not one was adopted. Between 1882 and 1904 not a single bill was introduced". HOVDE. "Notes on the Effects...", 1934, p. 257. 
nacional contra la emigración" ${ }^{32}$, que trató de ejercer un liderazgo activo en el uso de todo tipo de medios de difusión, tanto tradicionales como modernos, para trasladar a aquella parte de la población de la que procedían los emigrantes un estado de opinión contrario que consiguiera, por lo menos, reducir las cifras de partida ${ }^{33}$.

Lindkvist ha señalado las limitaciones de estos estudios, no por su calidad, sino por el estricto espacio cronológico que abarcan: haciendo una valoración de trabajos previos (comenzando por el de Kälvermark), afirma que "kännetecknande för flertalet av dessa studier är att de är begränsade och därför ger en något onyanserad bild av de politiska och ideologiska strömningar som påverkade reaktionerna i utvandringsfrågan» («Es característico de estos estudios que son limitados y por lo tanto presentan una visión en cierta medida simplista de las corrientes políticas de ideológicas que influyeron en las reacciones frente a la cuestión migratoria») ${ }^{34}$. Si bien su investigación, como muchos de los anteriormente citados, se centra nuevamente en el primer cuarto del siglo XX (específicamente las actividades de la Nationalföreningen mot emigrationen entre 1907 y 1925), Lindkvist intenta enmarcar los debates en torno a la reducción de la emigración en un contexto temporal más amplio ${ }^{35}$. Su conclusión es que, a lo largo del siglo XIX, en la sociedad sueca:

Ingen opinion hade då talat om behovet att bilda en förening för att hämma emigrationen, även om många sedan länge sett utvandringen som ett hot mot nationens framtid. Inte heller staten grep in för att hämma utvandringen mer än indirekt. Den svenska lagstiftningen som omgärdade utvandringen var tvärtom mycket tillåtande, särskilt efter att passtvånget tagits bort 1860. (...)Att

${ }^{32}$ Un testimonio temprano de la actividad de la asociación, en BERGHOLM, P. Nationalföreningen mot Emigrationen 1907-1917, Stockholm, NME, 1917.

${ }^{33}$ Sobre la Asociación nacional contra la emigración, su origen y actividades, véase LINDKVIST, A. Forden åt folket. Nationalföreningen mot emigrationen 1907-1925. Umeå (Suecia): Umeå universitetet, 2007.

${ }^{34}$ LINDKVIST, A. Forden åt folket. Nationalföreningen mot emigrationen 1907-1925. Umeå (Suecia): Umeå universitetet, 2007 (cit. en p. 19).

${ }^{35}$ LINDKVIST, forden åt folket...., 2007, capítulo "Reaktionen mot utvandringen" ("La reacción frente a la emigración", p. 35-56. 
utvandra var en medborgerlig rättighet $(. .)^{36}$.

No se expresó en consecuencia opinión alguna respecto a la necesidad de organizar un sistema para inhibir la emigración, aunque mucho tiempo se habia visto la emigración como una amenaza al futuro de la nación. Tampoco el Estado intervino para parar la emigración más que de un modo indirecto. La legislación sueca que regulaba la emigración era por el contrario muy permisiva, especialmente desde que se eliminó en 1860 el requerimiento del pasaporte.

(...) Emigrar era un derecho civil (..).

No obstante, opinión sobre la emigración no tiene por qué significar opinión contra la emigración, una confusión que hasta cierto punto se sitúa detrás de algunas de las afirmaciones vertidas en trabajos precedentes. En Suecia sí existió una reacción, en el debate público, respecto a la emigracion ya desde los comienzos del fenómeno. El hecho de que a lo largo del siglo XIX, como ya hiciera notar Scott, la mayor parte de los escritos suecos destinados a definir el estado público de opinión sobre América y la emigración no planteara una imagen peyorativa, sino más bien neutral o, en ciertos casos, positiva y "en general sin favorecer o desincentivar la emigración" 37 , no quiere decir que no existiera una preocupación por conocer, analizar y evaluar los datos, las motivaciones y los posibles efectos del fenómeno para la sociedad de partida. El mismo Scott advierte de que es preciso conocer todo el conjunto de valoraciones, propaganda, defensa y crítica de la emigración durante el siglo XIX, para entender la progresiva transformación de la imagen de la emigración en Suecia, especialmente a partir de su década final, que derivaría en la generalización y sistematización de un discurso claramente antiemigracionista ya entrado el siglo $\mathrm{XX}^{38}$.

\footnotetext{
${ }^{36}$ LINDKVIST, forden åt folket...., 2007, p. 42. La traducción del original sueco, como todas las que presentamos a lo largo de este trabajo, son nuestras.

${ }^{37}$ SCOTT, "Sweden's Constructive...", 1965, p. 308.

${ }^{38}$ SCOTT, "Sweden's Constructive...", 1965, p. 334.
} 


\section{La emigración en la prensa sueca (1861-1865): un análisis temático}

El presente trabajo se centra en un análisis temático de las referencias periodísticas sobre la emigración publicadas por la prensa sueca entre 1861 y 1865 . La selección de este periodo viene determinada por dos motivos. En primer lugar, se trata como hemos señalado con anterioridad del momento inmediatamente precedente a la primera gran oleada migratoria sueca hacia América. En segundo lugar, son los años de la Guerra civil entre federales y confederados en los Estados Unidos, que era por entonces prácticamente el único destino de la emigración sueca, como había sido desde sus mismos inicios dos décadas atrás, por lo que es posible aventurar como hipótesis que la situación bélica y su impacto en la opinión pública sueca ${ }^{39}$ influirían de un modo u otro en el debate existente en torno a la emigración. De hecho, como señalan Weibull y Fleisher, los estudios sobre la evolución de las corrientes migratorias suecas apuntan a que en estos años de guerra la emigración de los suecos a aquel país sufrió una gran reducción, sin llegar a una paralización total, en gran medida debido al deterioro de las condiciones de seguridad y fiabilidad del navegación y el comercio marítimo ${ }^{40}$.

Las referencias se han obtenido recurriendo al servicio Svenska dagstidningar de la Kungliga Bibliotek (Biblioteca Nacional de Suecia), en Estocolmo. Esta biblioteca conserva la mayor colección de prensa periódica editada en el país desde el siglo XVII, de la cual ha iniciado un proceso de digitalización comenzando por las trescientas cabeceras

${ }^{39}$ La prensa sueca hizo un seguimiento muy cercano y con abundantes noticias sobre el desarrollo de la guerra, sus contendientes, batallas, causas y consecuencias, como ya lo apuntaba el estudio de K. BONDESTAD. "The American Civil War and Swedish Public Opinion", Swedish-American Historical Quarterly, Chicago: n.19-2, p. 95-115, 1968.

${ }^{40}$ WEIBULL, J. y FLEISHER, E.W. Sverige Nordamerika: från upptäcktsfärd till linjefart, Stockholm, Almqvist\&Wiksell, 1954 (cit. en p. 60). También EKMAN, E. "Sweden and the Beginning of the American Civil War". In The Yearbook of American Swedish Historical Foundation, Bridgeport, The Chancellor Press Inc., 1961, p. 78-82. 
más importantes ${ }^{41}$. Esta digitalización incluye un vaciado del contenido de los artículos y noticias mediante sistemas OCR que permite hacer búsquedas sobre el propio contenido de los artículos, con un elevado nivel de precisión (especialmente para la prensa de la segunda mitad del siglo XIX en adelante, cuando se impone el uso de la tipografía europea frente a la germánica o gótica). Se usó como elemento básico de la búsqueda el radical utvandr- ("emigr-"), a fin de que incluyera todas las variantes posibles de palabras vinculadas a la emigración, añadiendo diversos elementos de refinación para evitar tanto la duplicación como, sobre todo, la inclusión de referencias erróneas o no centradas, específicamente, en la descripción o análisis de la emigración como fenómeno contemporáneo. Se trata de una palabra que aparece tímidamente en la prensa sueca comienzos de la década de 1840, y que para mediados de la década siguiente comienza a adquirir una presencia notable, si bien no sería hasta el último tercio del siglo cuando se dispara.

De este modo, para el periodo elegido, se localizaron un total de 976 artículos que cumplían las condiciones señaladas. De ellos, el 85,96\% se concentran en apenas cuatro cabeceras: el Aftonbladet de Estocolmo (fundado en 1830, de tendencia liberal), el Göteborgs-Posten (fundado en 1859, conservador), el Göteborgs Handels- och Sjöfarts-Tidning (liberal, fundado en 1819), ambos del puerto de Gotemburgo, y finalmente el Dagens Nyheter (de Estocolmo, aunque no saldría a la calle hasta diciembre de 1864) ${ }^{42}$ : a pesar del antes mencionado desarrollo de la prensa local y regional, se aprecia que el debate se concentró sobre todo en los periódicos de las dos principales ciudades del país, la capital y el principal puerto atlántico de Suecia, que tanto por su contenido como por el alcance de sus lectores potenciales eran los únicos que podían ca-

\footnotetext{
${ }^{41}$ Sobre la colección de prensa en la KG, y el alcance de la digitalización, véase la página web http:// www.kb.se/samlingarna/tidningar-tidskrifter/ consultada el 9 de diciembre de 2016.

${ }^{42}$ Las informaciones sobre estos periódicos, tomadas de GUSTAFSSON y RYDÉN. A History of the..., 2010, passim.
} 
talogarse, en cierto modo, como prensa de proyección nacional ${ }^{43}$. En un contexto más amplio, ampliando el radio temporal de la búsqueda hacia el resto del siglo, apreciamos que entre 1840 y 1900 se registran un total de 27.456 entradas, nuevamente centrándose casi dos tercios de ellas en seis cabeceras de las dos principales ciudades del país: Estocolmo (Aftonblated, Dagens Nyheter y Svenska Dagbladet) y Gotemburgo (Göteborgs Handels- och Sjöfartstidning, Göteborgs Aftonblad y Göteborgsposten).

a) La emigración como fenómeno continental: Un primer elemento que destaca cuando bajamos a estudiar el contenido concreto de las referencias es que prácticamente la mitad de ellas (un total de 472 artículos, noticias y sueltos) no se refieren específicamente a la emigración sueca a América, sino que recogen datos y comentarios sobre otros países europeos. Por cercanía, un buen número de las entradas periodísticas analizadas se refieren a otros países nórdicos (especialmente Noruega, que se hallaba por entonces unido dinásticamente a la corona sueca ${ }^{44}$ ), pero también Dinamarca, sobre todo en el caso de la prensa de Gotemburgo debido a la proximidad geográfica. No obstante, también abundan las referencias sobre emigración desde los estados alemanes o desde el Reino Unido; no en vano, Hamburgo ${ }^{45}$

${ }^{43}$ Por supuesto, no podemos dejar de lado el hecho de que exista una cierta infrarrepresentación de la prensa local y regional debido a los propios criterios de inclusón establecidos por la KG para seleccionar aquellos periódicos incluidos en la digitalización. No obstante, consideramos que tal infrarrepresentación es mínima: en los periódicos locales incluidos en la digitalización, así como en otros similares que consultamos en su versión original o microfilmada, se aprecia que el interés de las noticias no suele sobrepasar lo local, mientras que la prensa de Estocolmo y Göteborg suelen incluir informaciones remitidas desde diversas partes del país, en ocasiones incluso reproduciendo lo publicado anteriormente por esa misma prensa local.

${ }^{44}$ Las menciones a la emigración noruega suelen aparecer muchas veces vinculadas a la emigración sueca, debido además al hecho de que estadísticamente muchos países incluían ambos grupos en una misma tabulación. Además, cuando la prensa se hace eco de informaciones de procedencia oficial, como por ejemplo los informes consulares, suelen incluirse siempre datos tanto de suecos como de noruegos, dado que el servicio de representacion exterior era una de las pocas atribuciones, junto con la monarquía, comunes a ambos reinos. Por ejemplo: "Konsulsrapport. Utdrag af svenske och norske konsulns i Newyork", Aftonbladet, 1862-06-5, p. 3.

${ }^{45}$ La prensa de diversas localidades del sur de Suecia incluían durante estos años, por ejemplo, anuncios de la agencia fosef Hall $\mathcal{E}^{2}$ Son de Gotemburgo (situada en Södra Hamugatan, cerca 
y en menor medida Liverpool fueron los dos principales puntos de partida de emigrantes suecos antes de que se desarollaran las líneas que vinculaban directamente los puertos escandinavos con los Estados Unidos y otros países americanos ${ }^{46}$.

El origen de las noticias, que suelen ser por lo general informaciones recogidas de lo publicado en la prensa de otros países, hace que en muchos casos se refleje de un modo indirecto los términos del debate que sobre la emigración se dirimía en sus propias opiniones públicas. Encontramos así, por ejemplo, menciones al coste de los pasajes, a las denuncias de despoblación acelerada de pueblos enteros contagiados de la fiebre emigratoria o, como en el siguiente ejemplo, denuncias sobre engaños a los futuros emigrantes respecto a sus perspectivas laborales en América por parte de las empresas y agencias de emigración:

England. Från Liverpool meddelas att det till Newyork bestämda utvandrare-skeppet "Great Western" med omkring 500 emigranter ombord onsdagen den 16 denme blifvit anhället i Liverpools hamn af der vas rande myndigheter, på grund af erbälln-upplysningar om, att de flesta af utvandrara ne blifvit lockade att följa med genom bedrägliga förespeglingar om arbete i en stor gasfabrik strax efter deras ankomst till Amerika, medan den egentliga afsigten dock var att sälja dem för inträde i den nordamerikanska unionsarmeen.

Inglaterra. Comunican desde Liverpool que el barco de emigrantes "Great Western" que iba a salir hacia Nueva York con aproximadamente 500 emigrantes a bordo el jueves 16 quedó retenido en el puerto de Liverpool por las autoridades, en base a las revelaciones de que la mayoría de los emigrantes habian sido atraídos para continuar mediante falsas promesas

de los muelles), que representaba y vendía pasajes marítimos de la compañía Rob. M. Sloman de Hamburgo, cuyos barcos salían en viaje directo a Nueva York cada quince días. El anuncio afirmaba que "Af Herr Rob. M. Sloman ensamme bemyndigade till emottagande at utvandrare och passagerare för dessa fartyg, rekommendera vi desamma åt alla resande och utvandrare, under tillförsäkran om den bästa och samvetsgrannaste befodran" "“Como los únicos autorizados por el Sr. Rob. M. Sloman para recibir pasajeros y emigrantes para sus barcos, recomendados a todos los pasajeros y emigrantes que se aseguren la mejores promoción"). Fönköpingsbladet, 1965-02-14, p. 4.

${ }^{46}$ KEELING, D. "Transatlantic Shipping Cartels and Migration between Europe and America, 1880-1914”. Essays in Economic ङBusiness History, Mount Pleasant (Michigan): n.17, p. 195-213 (cit. en p. 200). 
de trabajo en una gran fábrica de gas nada más llegar a América, mientras que su verdadera intención era venderlos como reclutas para el ejército de la unión norteamericana ${ }^{47}$.

No obstante, el grueso de las noticias, como ya hiciera notar Scott, muestra un perfil mucho más neutro. Abundan las referencias puramente cuantitativas o estadísticas: recuentos hechos por las autoridades de los puertos de salidad o de entrada de emigrantes, o referencias a los datos publicados por países como Estados Unidos o Canadá respecto al número de inmigrantes recibidos anualmente, que solían hacerse públicos de manera periódica. Así, por ejemplo, los lectores del Göteborgs Handels- och Sjöfarts-Tidning pudieron saber, a comienzos de 1861, cómo "till Canada hafva år 1859 utvandrat 8,778 europeer, af hvilka 2,610 engelsmän, 1,248 irländare, 1,787 skottar, 1,100 tyskar och polacker samt 1,751 norrmän”48 (“A Canadá han emigrado en el año 1859 8.778 europeos, de los cuales 2.610 eran ingleses, 1.248 irlandeses, 1.787 escoceses, 1.100 alemanes y polacos así como 1.750 nórdicos ${ }^{49 "}$ ).

b) Además, también cuando el tema central hace referencia a emigrantes suecos, abundan las noticias "neutras"sobre la emigración: Bajo esta categorización incluyo aquellas entradas que se limitan a reflejar, de un modo descriptivo, episodios vinculados a la emigración de suecos sin entrar en otra categorización, explícita o implícita, que denote una toma de postura, favorable o contraria, a la decisión.

Este tipo de noticias se concentran, muy especialmente, en las páginas que la prensa de Estocolmo -y también la de Gotemburgo, aunque en menor medida- destina a recibir y transmitir noticias de las regiones interiores del país. Un ejemplo de este tipo de noticias la ofrece, por ejemplo, el siguiente breve enviado al Aftonbladet por su corresponsal en la localidad de Arvika (Värmland), que indicaba cómo:

\footnotetext{
47 "Utrikes", Upsala. Tidning för ekonomi och politik, 1864-11-29, p. 1.

48 "Till Canada", Göteborgs Handels- och Sjöfarts-Tidning, 1861-01-05, p. 2.

${ }^{49}$ Por "nórdico" se entiende en Suecia a los habitantes y originarios de Suecia, Noruega, Dinamarca, Finlandia, Islandia y sus dependencias. No debe confundirse con "escandivano", que solo incluye los tres primeros de dichos países.
} 
För omkring 10 år sedan utvandrade tvenne unga män vid namn Hult från Stafnäs socken, till Amerika, efter att här i orten på flera ställen hafva försökt sig i landthandel, hvilket ej ville bära sig. Efter att ut i guldlandet hafva förvärfvat sig några hundra tusen dollars beslöto de att åter resa till fäderneslandet på ett besök hos sina anförvandter och ankommo hit till orten för några veckor sedan, i afsigt som man trodde, att köpa sig egendom. De ämna snart återvända till Amerika $^{50}$.

Hace aproximadamente diez años emigraron dos jóvenes llamados Huld, de la parroquia de Stavnäs, a América, después de que habian intentado abrir un comercio en varios lugares en la ciudad, lo que no pudieron llevar a cabo. Tras haber ganado en el país del oro varios cientos de miles de dólares decidieron regresar a la patria para hacer una visita a sus parientes, y llegaron a la ciudad hace algunas semanas, con la intención como algunos creían de comprarse una propiedad. Decidieron pronto regresar a América.

El tipo de redacción que presentan estas noticias sobre emigrantes, cuando no se refieren a cuantificaciones, suelen centrarse en descripciones anecdóticas, en un estilo narrativo cercano a un microrrelato. El Folkets Röst (periódico antiliberal que funcionó en Estocolmo entre 1849 y 1861), por ejemplo, incluía en su edición del 3 de octubre de 1860 una pequeña historia en torno al intento fallido de emigrar de un adolescente:

En utvandringslysten svensk gymnasist hade under någon förevändning förstätt att af sina anhöriga förskaffa sig en betydligare penningesumma och inträffade för 14 dagar sedan i Hamburg, för att derifrån begifva sig till Amerika. Han tog logis hos en med honom bekant landsman och trodde sig sälunda säker för alla efterforskingar. Emellertid hade de bekymrade föräldrarne vändt sig till dervarande polismyndighet, hvilken det lyckades att häromdagen uppspåra den unge äfventyraren och taga honom i förvar. Denne var alldeles otröslig öfver det hinder, som lades i vägen för hans resa, och förklarade, att han i alla händelser, förr eller sednare, skulle sätta den i verket ${ }^{51}$.

\footnotetext{
50 "Från Arvika", Aftonbladet, 27 diciembre 1864, p. 2. La misma noticia, aunque de forma más detallada, en "Blandade ämnen", Göteborgs Handel- och Sjöfarts-Tidning, 28 diciembre 1864, p. 3. También en Göteborgsposten, 28 diciembre 1864, p. 1.

${ }^{51}$ Folkets Röst, 1860-10-03, p. 4.
} 
Un joven alumno sueco de secundaria deseoso de emigrar había conseguido de unos parientes con un pretexto una fuerte suma de dinero y llegó así hace 14 días a Hamburgo, de donde quería salir para América. Se alojó en casa de un amigo compatriota, creyendo que estaría a salvo de toda pesquisa. Sin embargo sus preocupados padres se pusieron a informar a la policía, que consiguió localizar al joven aventurero el otro día y tomarlo en su custodia. Es increíble como pudo superar los obstáculos puestos en el camino de su viaje, y declaró que, en cualquier caso, más pronto o más tarde, llevaría a cabo su empeño.

Ciertamente podría aducirse, en los ejemplos señalados, que detrás de una redacción aparentemente neutra podría incluso dejarse entrever una cierta imagen favorable, cuando no admirativa, especialmente respecto al éxito económico obtenido por los emigrantes suecos en el primero de los casos. No obstante, los discursos abiertamente favorables solían quedar circunscritos a dos tipos de referencia periodística: los anuncios clasificados, y las reproducciones de cartas de emigrantes ${ }^{52}$.

c) Los anuncios comerciales ofrecen un espacio privilegiado para ir más allá de los elementos ideológicos propios tanto de la línea editorial de los periódicos como, también, de la propia subjetividad de los periodistas y demás colaboradores de redacción de la prensa. Frente a la mediatización que ideología y subjetividad podían hacer sobre el contenido, la selección de las informaciones y la valoración sesgada del hecho descrito y analizado (en el caso que nos ocupa, las migraciones), los anuncios, por sus especiales características, nos abren una ventana para conocer los intereses, expresados de su manera más descarnada en su vertiente mercantil. La prensa, que precisa del soporte económico otorgado por los anunciantes tanto o más que de la venta directa de los ejemplares al público lector, puede incluso llegar a aceptar avisos comerciales contrarios a la propia línea ideológica que defiende en sus páginas de opinión ${ }^{53}$.

52 SCOTT, "Sweden's Constructive...", 1965, p. 308-309. Este autor hace mencion expresa a los anuncios y las "cartas americanas" como dos elementos que contribuyeron al mantenimiento y aumento de la corriente migratoria sueca en este periodo.

${ }^{53}$ En el caso de la prensa vasca, que hemos señalado con anterioridad, esta contradicción es especialmente evidente, debido al ya mencionado alineamiento, casi unánime, de los órganos periodísticos locales contra la emigración. Por ejemplo ÁLVAREZ GILA, O. "Argentinako 1890 urteko 
Soderberg cita la existencia de un creciente sistema de propaganda de la emigración a América ya desde la década de 1840, que se basaba primordialmente en la acentuación de los rasgos más positivos de la sociedad de destino y su capacidad de atracción: en esta propaganda, por lo general, "America was described as the land of freedom and promise, and a land flowing with milk and honey" 54 . No obstante, la propaganda comercial (es decir, de pago por el anunciante) vinculada a la emigración que se recoge en la prensa no tenía como objetivo tanto la promoción de la emigración en sí como la oferta de servicios de todo tipo para su adquisición y consumo por parte de aquellos que planeaban convertirse en emigrantes. Ya hemos citado antes ${ }^{55}$ algún ejemplo del tipo de propaganda más directamente vinculado a la emigración y, por otro lado, geográficamente más extendido: los anuncios de compañías navieras y agencias consignatarias que ofertan la venta de pasajes marinos para "pasajeros y emigrantes" hacia América. El negocio del transporte fue uno de los primeros que floreció en los principales puertos europeos al hilo del crecimiento del flujo emigrante. En este concepto se incluían, no solo las navieras que hacían las rutas transatlánticas, sino también otros elementos indisolublemente vinculados al tráfico marítimo de emigrantes, tal y como el traslado desde sus pueblos y países de origen hacia los puertos de partida, o el alojamiento y manutención de los mismos emigrantes mientras esperaban su embarque.

Algunos de estos anunciantes, incluso, ofrecían además del viaje otros servicios, dirigidos ya al proceso de instalación e inserción socioeconómica de los emigrantes una vez radicados en América: son los conocidos habitualmente como agentes de emigración. Aunque pocos, también se dejan ver en la publicidad publicada en la prensa sueca. Uno de los mejores ejemplos de este periodo lo ofrecen los anuncios publi-

krisialdiaren eragina Euskal Herriko emigrazioaren kontrako kanpainetan" ["La influencia de la crisis del año 1890 en Argentina en las campañas contra la emigración en el País Vasco”]. Muga, Bilbao: n.86, 1993, p. 32-45.

${ }^{54}$ SÖDERBERG. Den första mass..., 1981 p. 227.

${ }^{55}$ Ver nota 45. 
cados por O. Malmborg, residente en Gotemburgo, que se presenta como "Agente autorizado en Suecia" de la "Illinois Central-Jernvägs-Bolaget" (Illinois Central Railroad Company), ofreciendo oportunidades de trabajo y adquisición de tierras "a los suecos que tengan intención de emigrar a América":

(..) utbjuder emot låga priser och på lång kredit 1,200,000 tunnland särdeles rik och bördig skogs- och åkerjord samt stads-tomter, belgna i den blomstrande staten Illinois och nära vid banan ${ }^{56}$.

(..) ofrece para la venta a bajos precios y con créditos a largo plazo un millón doscientos mil acres de bosques y granjas particularmente ricos y fértiles asi como lotes urbanos, en el floreciente estado de Illinois y cerca del ferrocarril.

Otro bloque de anuncios, especialmente interesante porque no era habitual en otras regiones de Europa ${ }^{57}$, es el referente al mercado de libros dirigidos al consumo popular de los emigrantes. Scott ya señalaba que el comienzo de la emigración trajo consigo el surgimiento de un floreciente negocio de edición de "emigrant guidebooks, usually small pamphlets" ${ }^{58}$. En algunos casos nos encontramos con auténticos manuales prácticos destinados a avisar y proporcionar informaciones útiles sobre cómo emigrar y cómo instalarse en Amética. Uno de los primero ejemplos, igualmente destacados por Scott, es la obra "Beskrifn big ofver Nord-Amerikas Forenta Stater ... och rad for dem, somn

\footnotetext{
56 "Till Svenskar, som ämna utvandra till Amerika", Barometern, 1861-02-09, p. 3.

${ }^{57}$ Como señala Ångstrom, "The increasing number of books about America, both Swedish originals and translations, published in Sweden in the 1840's and '50's closely paralleled the growth of interest in the youth republic in the West. Once the Swedish emigration began in earnest, the flora of emigrant guide books and the newspaper articles devoted to America became rich indeed. As G.M. Stephenson says in his History of American Immigration: 'In no country in Europe have the America letters, emigrant guides, emigration agentes, and newspapers from America played a more active part than in the Scandinavian countries". ÅNGSTROM, M. "Swedish Emigrant Guide Books of the Early 1850's", American Swedish Historical Museum. Yearbook 1947, Philadelphia, 1947, vol. XI, pp. 28-48 (cit. en p. 22).

${ }^{58}$ SCOTT, “Sweden's Constructive...”, 1965, p. 308.for
} 
vilja dit inflytta" del pastor protestante Jonan Bolin ("Amplia descripción de los Estados Unidos de Norte América... y aviso para los que quieren inmigrar alli", Växjö, 1853): el autor había aclarado en su prólogo que su único objetivo era "to spread information by which the reader could judge whether he, for the sake of a safe and comportable living, and also for the purpose of enjoying natural and civil rights, would be best advised to move to the United States or to stay in the fatherland"59. Resulta además altamente significativo el hecho de que bastantes de los autores estén vinculados a la iglesia protestante sueca ${ }^{60}$. Tal es el caso, por ejemplo, de la obra "Bref i Andeliga Ämnen" ("Carta sobre la materia espiritual") del pasor Jonas Svensson, que se vende al precio de 25 centavos de corona como un "manual instructivo de religión para los compatriotas emigrados en Norte América" $"$.

En otros casos, se trata de biografías noveladas de emigrantes -en las que no se distingue ficción de realidad, aunque generalmente suelen presentarse como relatos verídicos y con un fin didáctico-, en las que se describe sus aventuras y desventuras en tierras americanas.

${ }^{59}$ SCOTT, "Sweden's Constructive...", 1965, p. 309. Un resumen de este manual, en FORSSEL, A. Emigranternas handledning, Stockholm, 1917, p. 8. Otras referencias sobre la edición de manuales de emigrantes, en SWANSON, R. "Some Swedish Emigrant Guide Books of the Second Half of the Nineteenth Century", Yearbook of the Swedish Historical Society of America 1926, St. Paul (Minnesota), 1926, vol. IX.

${ }^{60}$ No vamos a entrar en la cuestión de la opinión eclesiástica respecto a la emigración, sobre la que hemos trabajado previamente para el caso de la emigración vasca, y para la que esperamos poder hacer más adelante un estudio comparativo más profundamente (ALVAREZ GILA, O. "La Iglesia vasca frente a la cuestión migratoria: una visión de conjunto". Guregandik. Revista del centro de estudios Arturo Campión, Laprida (Argentina): n. 1, 2005, p. 9-20. También ALVAREZ GILA, O. "El euskaldun fededun y el americano descreído: la Iglesia vasca ante la emigración y el retorno". Boletín Hispano-Helvético. Historia, teoría(s), prácticas culturales, Berna (Suiza): n.21, 2013, p. 207-229). En todo caso, a diferencia de lo que ocurriera con la Iglesia católica en el País Vasco, la Iglesia protestante sueca no desarrolló una imagen totalmente negativa de la emigración y de la sociedad americana, en lo que respecta a la integridad religiosa de los emigrantes y colonos, como de hecho puede verse en el artículo publicado en febrero de 1863 que recogía diversas opiniones sobre la cuestión de pastores protestantes: "Prestetändet", Aftonbladet, 1863-02-07, p. 4.

61 "Evangelisk religions-lärare för utvandrade landsmän i Norra Amerika". "Bok-Annonser", Blekings-posten, 1862-12-12, p. 5. 
En diciembre de 1864, por ejemplo, diversos periódicos suecos daban cuenta de la aparición de una nueva obra puesta a la venta por el librero C.R. Hööks, titulada "Farmern och Guldgräfvaren eller En utvandrares Äfventyr i Virginien och Kalifornien för ungdomen bearbetad af Carl Müller. Med 4 lithografier" ("El granjero y el buscador de oro o la aventura de un emigrante en Virginia y California para jóvenes, escrito por Carl Müller. Con 4 litografias" ${ }^{62}$. Entre este tipo de obras, seguía gozando de un elevado éxito la autobiografía de uno de los pioneros de la emigración sueca en Estados Unidos: el libro "Minnen från en sjuttonårig vistelse i Nordvestr Amerika" ("Recuerdos de una estancia de diecisiete años en América del Noroeste") de Gustaf Unonius ${ }^{63}$.

d) Las cartas de emigrantes, por su parte, acabaron por convertirse en todo un genero periodístico en la prensa sueca durante estos años, bajo epígrafes generalmente denominados "Bref från Amerika" ("Carta desde América") o, simplemente "Från Amerika" ("Desde América"). Si bien el género epistolar, por definición, pertenece más al ámbito de las comunicaciones privadas que de la opinión pública, la prensa pronto adoptó la práctica de editar transcripciones de algunas de las misivas enviadas por emigrantes, derivando el género hacia la publicación de auténticos reportajes descriptivos, remitidos por corresponsales informales a las propias redacciones de los periódicos, estas sí con el objetivo de ser difundidas públicamente (a diferencia de las primeras cuyo traslado a la prensa habría sido, en todo caso, una acción no prevista, y quizá no deseada, por su autor ${ }^{64}$.

El uso de la correspondencia epistolar y otros tipos de documentación privada tiene ya un largo recorrido en los estudios históricos sobre

\footnotetext{
62 "Bok-Annonser", Nyare Blekings-posten, 1864-12-20, p. 4.

63 "Bok-Anonser", Aftonbladet, 1861-10-12, p. 4. Unonius había sido el lider de la primera expedición de emigrantes suecos que se asentaron en la zona de Wisconsin, donde fundaron un pequeño asentamiento que llamaron "Nya Uppsala". La familia de Unonius regresó a Suecia en 1858, publicando entre 1861 y 1862 sus memorias, en las que describía de un modo idealizado su experiencia americana.

${ }^{64}$ SCOTT, "Sweden's Constructive...", 1965, p. 309.
} 
migraciones ${ }^{65}$. Desde que Thomas y Znianiecki analizaran las migraciones polacas a Estados Unidos mediante la recopilación y análisis de cartas personales en su The Polish Peasant in Europe and America (19181920), estas fuentes se han venido utilizando como un contrapunto de las visiones reduccionistas y empiricistas, buscando ver en el sujeto (el emigrante) un agente de su destino, más allá de las condiciones objetivas que pudieran determinar sus decisiones ${ }^{66}$. Los resultados, en todo caso, han sido diferentes, y en muchos casos menores a lo esperado. Como señada Blanck:

Over the years, different conclusions as to what we can learn from these letters have been drawn, and what they really tell us about the nature of the immigrant experience has been a topic for debate. Historians in Sweden, for example, had high expectations of the Swedish immigrant letters when that academic profes- sion took up the study of Swedish immigration in earnest in the 1960s, but were soon disappointed that many letters contained relatively little factual information, but instead were quite formulaic ${ }^{67}$.

Para la prensa que las publicaba, sin embargo, la correspondencia, y sobre todo las cartas privadas enviadas por los emigrantes a familiares y amigos, jugaban un papel muy diferente. Básicamente, los periódicos buscaban en el género epistolar no solo una fuente directa y fresca de informaciones en un momento en el que no existían medios rápidos y abundarles para obtenerla, sobre todo si venían del otro lado del océano, sino también y sobre todo disfrutar en su publicación del plus de veracidad que se suponía que debía atribuirse a lo transmitido por este medio. Además, no hay que olvidar lo que destaca Øverland en su obra From America to Norway: el rol que jugaban las cartas como

${ }^{65}$ Nos remitimos a nuestro análisis introductorio en el prefacio de la obra ALVAREZ GILA, O. y ANGULO MORALES, A. (dirs.) From the Records of My Deepest Memory. Personal Sources and the Study of European Migration, 18th-20th Centuries, Bilbao, University of the Basque Country, 2016 (cit. en p. 9-12).

${ }^{66}$ STANLEY, L. "To the Letter: Thomas and Znaniecki's The Polish Peasant and Writing a Lifre, Sociologically". Life Writing, Londres: n.7/2, 2010, p. 139-151.

${ }^{67}$ BLANCK, D. "Reseña de la obra From America to Norway. Norwegian-American Immigrant Letters 18381914", American Studies in Scandinavia, Helsinki: n.45-1/2, pp. 171-172, 2013. 
piezas de propaganda -ya fuera positiva o negativa- para futuros emigrantes a América ${ }^{68}$.

Desde este punto de vista, resulta altamente significativo calibrar cuál es la selección de cartas que la prensa optaba por publicar, especialmente en lo que se refiere a la visión que ofrecían sobre América como tierra de posibilidades, así como a la valoración que los autores de las misivas podían hacer sobre su propia experiencia migratoria. ¿Era tal valoración positiva o negativa? Hemos localizado un total de 50 referencias identificadas como "cartas" enviadas por emigrantes en el periodo estudiado, y la imagen que traslucen está lejos de ser simplista. No hay, en este punto, una unanimidad: se publican, de este modo, algunas cartas que buscan de manera clara disuadir a los candidatos a convertirse en futuros emigrantes. Así hacía, por ejemplo el periódico local Norrköpingskuriren, cuando en diciembre de 1862 recogía, no exactamente una carta, sino el testimonio personal de un emigrante retornado:

Enligt Nerikes Allahanda har v. pastor Lindgren, som utvandrat till Kalifornien i akt och mening att som prest betjena dervarande svenskar, återkommit till faderslandet, emedan förhållandena voro sådana att han ej kunde qvarstanna. Han yttrar bland annat: På det allvarligaste varnar jag hvar och en af mina landsmän för en utvandring till Amerika och i synnerhet till Kalifornien; ty ingen, som ej sett det, kan ana, hvilket glädejlöst lif, hvilka faror och mödor der möta. Fullkomligt säkert är det, att ingen hederlig person der uppmanar någon till utvandring dit. Det tarfligaste uppehålle här, med redlighet förvärfvadt, är mångfaldiga gånger bättre än lifvet i Kalifornien ${ }^{69}$.

${ }^{68}$ ØVERLAND, O. (editor and translator). From America to Norway. Norwegian-American Immigrant Letters 1838-1914, Northfield (Minnesota), Norwegian-American Historial Association, 2012.

69 "Norrköping den 16 december", Norrköpingskuriren, 1862-12-16, p. 2. 
Informa el Nerikes Allahanda que ha regresado a la patria el h. pastor Lindgren, que emigró a California con la intención de ejercer su ministerio en beneficio de los suecos, porque las condiciones eran tales que no podía permanecer allí. Afirmó entre otras cosas: Con toda seriedad prevengo a todos y cada uno de mis conciudadanos de emigrar a América y especialmente a California; porque nadie, si no lo ha visto, puede imaginar qué vida triste, qué peligros y dificultades se va a encontrar allí. Lo que es completamente seguro es que ninguna persona honesta debe invitar a nadie a emigrar alli. La casa más humilde aquí, con toda su integridad, es muchas veces mejor que la vida en California.

No era esta, sin embargo, la tónica más habitual. La mayor parte de las cartas publicadas no presentaban, de hecho, una intencionalidad tan marcada, ni para evitar ni para promover la emigración. Se trataban más bien de misivas de índole claramente informativa, algunas de ellas describiendo sucesos interesantes de la vida y actividades de las colonias de emigrantes suecos en Estados Unidos ${ }^{70}$, y otras, incluso, dedicadas a proporcionar avisos y consejos prácticos sobre cuestiones vinculadas al viaje, el comportamiento de las navieras, el modo de enfrentarse a la burocracia de inmigración en el puerto de destino, o las posibilidades laborales y niveles de salario que podían encontrar los inmigrantes. Un buen ejemplo de este tipo de cartas la publicó el diario holmiense Dagens Nyheter en enero de 1865. La "bref från Amerika" publicada en esta ocasión se identifica como enviada por un nativo de Jönköping que había emigrado poco tiempo antes a Nueva York. En esta carta, tan larga como interesante, su autor desgrana diversas recomendaciones para otros que quieran seguir sus pasos. En primer lugar, realiza una completa comparación sobre los costes (pecuniarios, de tiempo y de esfuerzo) del viaje transatlántico entre la opción de partir del puerto de Copenhague, como él había hecho, respecto a los dos puertos más habituales de los que salían los suecos, Hamburgo y Liverpool. Seguidamente advertía sobre el comportamiento de las compañías navieras: "Emigrant- och ångfartygbolagen vilja ej ansvara för de resandes effekter. I hyttén kan man ej hafva mer än en liten

\footnotetext{
${ }^{70}$ Por ejemplo, entre otros: "Lifvet och utkomsten i Amerika", Dagens Nyheter, 1865-02-07, p. 3. También "En landstigning i Norra Amerika", Dagens Nyheter, 1865-02-28, p. 3.
} 
kappsäck, som det ibland är svårt nog att få ega i fred" ("Las compañías de emigracion y de vapores no se hacen responsables de los efectos de los pasajeros. En la cabina no se puede tener más que una maleta pequeña, que a veces es muy dificil de poseer en paz"). Finalmente, tras describir los servicios de traductores que ayudan a los nórdicos en los trámites de inmigración a los Estados Unidos, acaba por mostrar un panorama realista de las oportunidades del Nuevo Mundo:

En del af de emigranter, som medföljde på samma skepp som jag, har jag lyckats att genom den lilla kännedom jag eger i engelska språket förskaffa arbete, men vida mer ansträngande än hemma i Sverge, och likväl är dagspenningen ej stort men än 2 rdr 50 öre ${ }^{71}$.

Una parte de los emigrantes que llegaron en el mismo barco que yo, he podido saber con el poco conocimiento que tengo del idioma inglés que han encontrado trabajo, aunque mucho más intenso que en Suecia, si bien el salario diario no es mayor de 2 coronas y 50 centavos.

No obstante, las cartas más interesantes son aquellas que reflejan una visión claramente positiva de la emigración. En marzo de 1865 el mismo diario publicaba una nueva "carta de un emigrante en América". En la introducción se aclara que el autor de la carta es "un trabajador que marchó con Ernst Merkc el pasado verano" a Michigan, y que la breve misiva -que se centra en cuestiones económicas- había sido enviada "a un amigo en Estocolmo”. El anónimo emigrante no solo mostraba las facetas más atractivas de su experiencia emigratoria, sino que se atrevía incluso a criticar ciertas informaciones negativas sobre la emigración que aparecía en "lo que escriben en los periódicos de Estocolmo":

Jag tycker det är ganska bra här - dubbelt bättre än i Stockholm, inga dyra hyror, ingen dyr skatt som i Sverge - fri och ledig att gå hvart man vill.

\footnotetext{
71 "Bref från Amerika", Dagens Nyheter, 1865-01-13, p. 4. El redactor señala, además, que el original de la carta había sido publicado con anterioridad en el periódico local fonköpingsbladet, aclarando igualmente que se trata de una región de la que parten abundantes emigrantes.
} 
Jag får tala om för dig att vi som skulle till Portland brefvo fria från resekostnaden. Vi ginfo gå hvart vi ville. Hvad de skrifva i tidningare i Stockholm om slaveri är den största osanning de kunna hitta på.

Här finns arbete och äfven mat. Bränvin är dyrt men inte godt och det begagnas litet Arbetslönen är 2 1/2 a 3 dollars om dagen och en pappersdollar är ungefär 2 rdr svenskt mynt. Maten för en ungkarl kostar 10 a 20 dollars i månaden, och jag önskar du vore här så skulle du finna dig bättre än i Sverge ${ }^{72}$.

Creo que se está muy bien aquí - el doble de bien que en Estocolmo, la renta no es alta, ni hay impuestos altos como en Suecia - y además uno es libre de ir donde quiera.

Te puedo decir que los que fuéramos hasta Portland estaríamos exonerados del coste del viaje. Podríamos ir donde quisiéramos. Lo que escriben en los periódicos de Estocolmo sobre esclavitud es la mayor mentira que pueden encontrar.

Aquí se encuentra trabajo e incluso comida. El licor es barato aunque no es bueno y se usa poco. Los salarios son de 2'5 a 3 dólares al día y un billete de dólar vale aproximadamente dos coronas suecas. La comida para un soltero cuesta de 10 a 20 dólares por mes, y yo desearía que estuviéras aquí porque estarías mejor que en Suecia.

\section{e) La prensa también se introdujo, finalmente, en el de-} bate sobre las causas de la emigración.- En este punto, la prensa sueca coincidía, no solo con sus colegas del periodismo en otros países con fuerte desarrollo de la emigración, sino también con las incipientes reflexiones que las nacientes ciencias humanas estaban comenzando a elaborar para dar respuesta a un fenómeno que, por su visibilidad y relevancia numérica, había concitado al mismo tiempo la atención de pensadores, políticos, opinadores y cientificos. Y el debate tenía también una doble faz: la discusión entre los factores de expulsión (push) y de atracción (pull) entre los elemento explicativos de la emigración.

Sobre los factores de expulsión, los diversos periódicos eran bastante coincidentes en sus planteamientosy justificación. La economía se presenta, desde el principio, como el principal causante del éxodo; y más concretamente, la falta de modernización del tejido productivo, y sobre todo, de la industria sueca. Curiosamente, uno de los artículos

72 "Bref från en utvandrare till Amerika”, Dagens Nyheter, 1865-03-22, p. 2. 
que incide de un modo más completo y complejo en la vinculación entre atraso económico y boom migratorio no se centra específicamente en discutir la migración, sino que se inserta en la descripción comentada que hace el diario Aftonbladet respecto a una sesión del parlamento sueco, en enero de 1865, en la que se produjo un debate entre los defensores del proteccionismo y del liberalismo económico, discutiendo sobre el futuro de la industria de Suecia. Según recoge el cronista, los argumentos del bando proteccionista incidieron en dos cuestiones: la necesidad del ahorro y la protección de los trabajadores. A este respecto, un orador, poniendo como ejemplo la región de Norrköping, señalada cómo:

Då upphäfdes ännu värre rop om landets stundande ruin och de understöddes med vidlyftiga sifferkalkyler, hvarmed man denna gång icke besvärat sig och oss. Man talade om att hela provinsers befolkning skulle nödgas utvandra till Amerika och hotade att nedlägga alla fabriker, all industri för att straffa det otacksamma fäderneslandet ${ }^{73}$.

Entonces lanzaron un lamento aún mayor sobre su inminente ruina, y se apoyaron en voluminosos cálculos y cifras, con los que esta vez no iban a aburrirse ni a aburrirnos. Se habló de toda la población de provincias que tendrían que emigrar a América, y amenazaron con el cierre de todas las industrias, de todas las industrias para castigar a la patria ingrata.

Se unía a esto, tímidamente, alguna mención a la labor de reclutadores y agentes de emigración si bien, a diferencia de los términos del debate en otros países, el argumento no se centraba tanto en la demonización de la figura y actividad de estas personas (encargadas o comisionadas para reclutar nuevos emigrantes en los países de origen) como, sobre todo, en las causas económicas subyacentes que permitían que su labor de propaganda tuviera una respuesta amplia, como por ejemplo, en la campaña desarrollada en el invierno de 1865 en diversas regiones

73 “Stockholm den 23 Jan", Aftonbladet, 1865-01-23, p. 1-2 (cit. en p. 2). 
de Suecia, donde según la prensa los reclutadores fueron capaces de hacerse con varios miles de personas deseosas de marchar a América:

Nya värfningar för Amerika. Nerikes Allehanda berättar, att värfningar för utvandring till Amerika pågått i stor skala hela vintern inom Nora, Carlskoga, Filipstads m.fl. bergslager. Tidningen har hört uppgrifvas, men anser det dock otroligt, att 5000 till 7000 personer skola låtit värfva sig. Fattiga och rika, dugliga och odugliga arbetare, skräddare och skomakare, qvinor och barn — alla hållas till godo af värfvaren, som denna gången skall vara en svensk, som för flera år sedan utvandrat från Carlskoga, men sedan återkommit för att locka sina landsmän att följa exemplet ${ }^{74}$.

Nuevos reclutamientos para América. El Nerikes Allehanda dice que se han realizado reclutamientos a gran escala para emigrar a América durante todo el imvierno en Nora, Karlskoga, Filipstad y en otros muchos lugares. El periódico ha sido informado, aunque lo considera increible, que entre 5000 y 7000 personas se hayan dejado reclutar. Pobres y ricos, trabajadores calificados y sin calificar, sastres y zapateros, mujeres y niños - todos han sido llevados para beneficio del reclutador. que en esta ocasión es un sueco que hace varios años emigró desde Karlskoga, pero que ahora regresó para convencer a sus compatriotas a seguir su ejemplo.

Por otro lado, si bien como ya hemos señalado anteriormente los años de la Guerra Civil en Estados Unidos provocaron una ralentización en la emigración suecia hacia aquel país, la prensa paradójicamente no veía en la misma guerra un motivo para siquiera advertir contra los posibles peligros a los que podían enfrentarse los emigrantes. La guerra en sí no era un tema desconocido en modo alguno para la opinión pública en Suecia; antes al contrario, tuvo una gran repercusión en la prensa y se convirtió, durante todo el tiempo que duró, en uno de los generadores de noticias más destacados. Como

74 "Nya värfningar för Amerika", Aftonbladet, 1865-03-30, p. 2. También se hace eco de la noticia el otro periódico de Estocolmo: "Nyheter från Stockholm", Dagens Nyheter, 1865-03-30, p. 2, que relaciona directamente la recluta con la situación económica y añade que los emigrantes han sido reclutados "för att utvandra till Amerika och arbeta i grufvor" ""para emigrar a América y trabajar en las minas"). Tambien el Göteborgsposten, 1865-04-01, p. 2-3, se hace eco de la noticia, aunque de un modo mucho más breve. 
señalan Weibull y Fleisher, los suecos, por lo tanto, pudieron seguir la guerra con la cercanía que permitían los medios de comunicación del momento, y desde el sentimiento provocado por la existencia de una incipiente colonia de compatriotas viviendo ya en diversos estados del norte de los Estados Unidos de América ${ }^{75}$. También existían de por medio razones de índole económico, debido a los fuertes intereses mercantiles creados por la propia guerra, que generaron una creciente demanda de importaciones de hierro sueco, dirigidas casi exclusivamente al bando nordista ${ }^{76}$. La opinión pública sueca, por estos y otros motivos, se decidió casi de forma unánime en favor de los nordistas; lo que, como recogen entre otros Hokanson, ${ }^{77}$ Åberg $^{78}$ o más recientemente Liederg ${ }^{79}$, hizo que en el seguimiento que la prensa sueca hizo del conflicto fueran especialmente bien recibidas las victorias militares de la Unión frente a los confederados.

De hecho, siguiendo a lo reflejado en la prensa, podría incluso llegar a pensarse que la guerra no solo no era un elemento disuasorio para futuros emigrantes, sino que los atraía. A lo largo de los años que duró el conflicto se repitieron las noticias y artículos que glosaban y hasta cierto punto ensalzaban, no solo la participación activa de suecos (así como de noruegos y otros nórdicos) en la contienda defendiendo el uniforme de la Unión ${ }^{80}$, sino también aquellos casos conocidos de personas que habían decidido emigrar, precisamente, para alistarse en aquel ejército. Así por ejemplo, en la sección de noticias de Dinamarca del Göteborgs Handels- och Sjöfarts-Tidning, en diciembre de 1864, se

\footnotetext{
${ }^{75}$ WEIBULL y FLEISHER, Sverige Nordamerika..., 1954, p. 60-64.

${ }^{76}$ WEIBULL y FLEISHER, Sverige Nordamerika..., 1954, p. 69.

${ }^{77}$ HOKANSON, N. Sivedish ImmigrantsinLincoln's Time. New York/Londres:Harper\&Brothers, 1942,p. 146.

78 ÅBERG, A. Svenskarna under stjärbaneret: insatser under nordamerikanska inbördeskriget 1861-1865, Stockholm: Natur och kultur, 1994, p. 70.

${ }^{79}$ LIEDERG, G. En amerikanskslavjakt - Attityder i Sverige ochi Östgöta Correspondenten angående det amerikanska inbördeskriget, C-uppsats dissertation, Enheten för Historia, Linköpings Universitetet (Suecia), 2010, p. 16-30).

${ }^{80}$ En "Soldatpressningen i Amerika", publicado en Aftonbladet (1865-01-09, p. 2), por ejemplo, se reproducía entre elogios la carta de un noruego llamado Nils Martin Hansen, publicada previamente en el Bergen Post, en el que tras hablar de su viaje a América describía su participación en la guerra tras enrolarse en el ejército del Norte.
} 
daba cuenta de cómo "en stor del danska officerare hafva efter erhållat afsked utvandrat till Norra Amerika för att taga tjenst ir nordstaternas armé" ("una gran parte de la oficialidad danesa, tras haber sido licenciada, ha emigrado a Norte América para tomar servicio en el ejército de los nordistas" ${ }^{81}$. Las descripciones podían llegar incluso a tomar rasgos sorprendentes, como en el siguiente caso en el que, además, se mezclaba religión y política de un modo, cuando menos, sorprendente:

En afkomling af Luther. En af den store reformatorns afkomlingar som varit bosatt i Schönbeck vid Magdeburg, har nyligen utvandrat till Amerika, hvarest man af aktning för hans stamfar anställt honom såsom divisionspredikant vid unionsarmén, oaktadt han icke gjort några teologiska studier.

Un descendiente de Lutero. Uno de los descendientes del gran reformador que vivía en Schoenbeck, cerca de Magdeburgo, ha emigrado recientemente a América, y como muestra de respeto a su antepasado lo reclutaron como predicador de división en el ejército de la Unión, a pesar de que no contaba con ningún estudio teológico.

Solo en algunas contadas ocasiones se apunta la remota posibilidad de que la emigración pudiera dirigirse a otros destinos alternativos en el mismo continente americano, al hilo de breves noticias que informaban sobre la partida de emigrantes irlandeses a México ${ }^{82}$, noruegos a Argentina ${ }^{83}$ e islandeses a Brasil $^{84}$, si bien la prensa, incluso en los peores años de la contienda, nunca llegó a presentar argumentos sólidos que pudieran servir para defender tal postura.

\footnotetext{
81 "Från Danmark", Göteborgs Handels- och Sjöfarts-Tidning, 1864-12-12, p. 2.

82 "Kejsardömet Mexico", Göteborgs-Posten, 1865-02-14, p. 1.

83 "Från Norge", Göteborgs-Posten, 1863-11-27, p. 1. También "Norge", Aftonbladet, 1863-11-24, p. 3

84 "Från Island", Aftonbladet, 1865-08-30, p. 2. Esta noticia es especialmente interesante, porque ofrece una pista interesante sobre una pequeña emigración de aproximadamente unos 200 islandeses que se habrían dirigido en 1865 a Brasil, y de la que no tenemos otra noticia: "Såsom en kontrast till denna nordiska kolonisation kunna vi anföra isländarnes vaknade lust att utvandra till Brasilien. Redan förra året afreste dit några bönder från Nordlandet och nu ämna omkring 200 män från Thingö-syssel försöka sin lycka i denna verldsde" "Como contraste a esta colonización nórdica podemos citar el deseo despertado a los islandeses por emigrar a Brasil. Ya el año pasado se fueron alli algunos agricultores de la tierra del Norte y ahora 200 hombres de Thingö tienen el propósito de probar suerte").
} 


\section{Conclusiones}

La opinión pública sueca, como ocurriera en otros países europeos, reaccionó pronto ante el progresivo aumento de la emigración ultramarina a América y, por lo tanto, se desarrolló en la prensa escrita un interés por conocer, analizar y debatir las implicaciones que la emigración tenía, tanto para los propios emigrantes como para la sociedad sueca en su conjunto. El análisis de un momento relativamente temprano en el proceso migratorio, la primera mitad de la década de 1860, refuerza la noción de que la prensa en modo alguno fue indiferente a la creciente realidad de la emigración. A diferencia de lo que se ha apuntado en ocasiones, tal reacción no fue tardía, si bien no fue ni unánime ni mayoritariamente contraria a la emigración, al menos durante muchas décadas a lo largo del siglo XIX. La prensa sueca, en este punto, no se decidió de manera evidente por una visión sesgada o parcial de la emigración, ya fuera esta negativa (como ocurrió de forma mayoritaria, por ejemplo, en España) o positiva, sino que, a pesar de que en las páginas de la prensa se recogieron tanto opiniones favorables como desfavorables, el tono general y de conjunto refleja más bien una posición de neutralidad, o cierta equidistancia. Aunque la prensa advertía -sobre todo de un modo didáctico, como medio de aviso a los futuros emigrantes- de las dificultades, peligros y otros riesgos que podían correr los que se decidían a trasladarse a América, también es cierto que abundaron por el contrario las referencias a la pujanza y apertura de la economía y la sociedad americanas (sobre todo las de Estados Unidos, país que durante todo el periodo atrajo a la inmensa mayoría de los emigrantes suecos), y unida a ello, de las historias de éxito y ascenso protagonizadas por emigrantes compatriotas.

En esta visión coincidían, igualmente, otros sectores de singular importancia en la conformación de la opinión, y en especial la Iglesia reformada sueca, cuya actitud ante la emigración (nuevamente en contraste, de manera especial, con la actitud de la Iglesia católica en España o Italia) estuvo lejos de mostrarse militantemente contraria a la emigración. Si bien las diversas instituciones eclesiales de Europa compartían una misma base en la comprensión del fenómeno, sobre todo 
en el convencimiento de la necesidad de ofrecer una atención especial al "cuidado espiritual" de los emigrantes (procurando que la lejanía geográfica de la patria no significara un alejamiento de su fe religiosa), diferían en el modo de llevar a la práctica el modo de contrarrestarlo. En Suecia la respuesta fue, básicamente, el traslado a América de la propia iglesia, sus instituciones, pastores y libros, acompañando a los emigrantes desde el mismo viaje.

Además, la Iglesia sueca, como el conjunto de la sociedad, no tenía una visión negativa de América. Antes al contrario, América (entendida primordialmente como los Estados Unidos) se convertiría a lo largo del siglo XIX en el espejo en el que se miraban quienes deseaban la modernización socioeconómica de Suecia. Solamente con el cambio de siglo, cuando la intensificación de la emigración vino de la mano de la intensificación de los debates modernizadores y la aceleración de la transformación económica, pasó la emigración de ser un reflejo del atraso del país a causa de todos sus males.

Recebido: 16/05/2017 - Aprovado: 17/08/2017 